\title{
Vascular and renal telomere shortening in mice exposed to chronic intermittent hypoxia
}

Mohammad Badran $\mathrm{PhD}^{1}$, Bisher Abuyassin $\mathrm{PhD}^{2}$, Najib Ayas $\mathrm{MD}^{3}$, Don D. Sin $\mathrm{MD}^{4}$, Ismail Laher PhD ${ }^{* 5}$

${ }^{1}$ Department of Child Health and the Child Health Research Institute, University of Missouri School of Medicine, Columbia, MO, USA

${ }^{2}$ Experimental Medicine Department, King Abdullah International Medical Research Center/King Saud bin Abdulaziz University for Health Sciences, King Abdulaziz Medical City, Ministry of National Guard Health Affairs, Riyadh, Saudi Arabia

${ }^{3}$ Divisions of Critical Care and Respiratory Medicine, Department of Medicine, University of British Columbia; Sleep Disorders Program, UBC Hospital; Division of Critical Care Medicine, Providence Health Care, Vancouver, British Columbia, Canada

${ }^{4}$ The University of British Columbia Center for Heart Lung Innovation (HLI), St Paul's Hospital, and Division of Respiratory Medicine, University of British Columbia, Vancouver, BC, Canada

${ }^{5}$ Department of Pharmacology and Therapeutics, Faculty of Medicine, University of British Columbia, Vancouver, British Columbia, Canada

\section{*Author for correspondence}

Department of Anesthesiology, Pharmacology and Therapeutics,

Faculty of Medicine, University of British Columbia,

Vancouver, BC, Canada, V6T $1 Z 3$.

Email: ismail.laher@ubc.ca

Phone number: +001 (604) 822-5142

WOD COUNT: 824 


\begin{abstract}
:
Obstructive sleep apnea (OSA) is a chronic condition characterized by chronic intermittent hypoxia (IH) and is associated with cardiovascular (CVD) and chronic kidney diseases (CKD). There is increased biomarkers of aging, such as telomere shortening, in patients with OSA. We assessed telomere lengths in aortic and renal tissues from mice exposed to 8 weeks of IH using a PCR protocol, and demonstrate significant telomere shortening in both tissues. This data indicates that IH, a hallmark of OSA, can accelerate vascular and renal aging that may contribute to OSA-induced CVD and CKD
\end{abstract}

\title{
Introduction
}

Obstructive sleep apnea (OSA) is a chronic condition characterized by repetitive episodes of airway collapse inducing intermittent hypoxia $(\mathrm{IH})$ and sleep fragmentation, and is considered an independent risk factor for many conditions such as cardiovascular (CVD) and chronic kidney diseases (CKD) $(1,2)$. Prominent underlying pathological mechanisms involved in OSA-induced CVD and CKD are inflammation and oxidative stress (3). Telomere shortening, a biomarker of aging and cellular senescence that is influenced by oxidative stress (4), is associated with CVD and CKD $(5,6)$. While telomere attrition in leukocytes has been documented in OSA patients (7), it is unknown whether the obstructive events leading to intermittent hypoxia can shorten telomeres in peripheral organs such as the aortic vasculature and kidneys. In this experiment, we exposed mice to 8 weeks of chronic intermittent hypoxia $(\mathrm{IH})$ and measured telomere length in aortic and kidney tissues.

\section{Methods}

IH protocol: Male C57BL/6 mice (8-10 weeks old, 25-30 grams) were housed in customized cages placed in a room with a $12 \mathrm{~h}$ light-dark cycle $(07: 00 \mathrm{~h}-19: 00 \mathrm{~h})$ at a constant temperature $\left(26^{\circ} \mathrm{C}\right)$. A gas control delivery system regulated the flow of room air and $\mathrm{N}_{2}$ into the customized cages to control the inspired $\mathrm{O}_{2}$ fraction $\left(\mathrm{FiO}_{2}\right)$ levels in each cage. The level of $\mathrm{FiO}_{2}$ was reduced from $20.9 \%$ to $5.0 \%$ over a $30-\mathrm{s}$ period and rapidly returned to room air levels using a burst of $100 \% \mathrm{O}_{2}$ during the following 30 -s period for $12 \mathrm{hrs}$ daily during the light cycle. This IH paradigm generates oxyhemoglobin nadir values in the 50$60 \%$ range. Mice were exposed to room air throughout the 12-h dark cycle (when mice are active). For the intermittent air (IA, control) group, normoxic gas was flushed periodically into the chambers over $24 \mathrm{hrs}$ at the same frequency as the protocol for inducing $\mathrm{IH}$. Mice were exposed to either the chronic $\mathrm{IH}$ or intermittent air (control) for 8 weeks (8).

Telomere length: The telomere lengths of mouse aortic and kidney tissues were measured using a qPCR protocol as described previously by Callicott and Womack (9). In brief, the assay measures the amount of telomeric DNA per sample as a ratio to the total amount of genomic DNA, which is given by the measurement of acidic ribosomal phosphorprotein PO (36B4) gene. Telomeric forward and reverse primer sequences (Sigma, The Woodlands, TX) were (5] $\rightarrow 3$ ? $)$ ) CGG TTT GTT TGG GTT TGG GTT TGG GTT TGG GTT TGG GTT and (5? $\rightarrow 3$ ? ]) GGC TGG CCT TAC CCT TAC CCT TAC CCT TAC CCT TAC CCT, respectively, while murine 36B4 forward and reverse primer sequences were (5? $\rightarrow 3$ ? $)$ ACT GGT CTA GGA CCC GAG AAG and (5] $\rightarrow 3$ ? $)$ TCA ATG GTG CCT CTG GAG ATT, respectively. Measurements were performed in triplicates per sample on 384-well Clear Optical Reaction Plates (Applied Biosystems, Foster City, CA). A sample of DNA extracted from the lung tissue of a C57BL/6J mouse was added to each plate to serve as a reference. Calculations for telomere length over single copy gene ratio ( $T / \mathrm{S}$ ratio) for each sample were compared to the $\mathrm{T} / \mathrm{S}$ ratio of the reference DNA and expressed as relative telomere length. 


\section{Results and Discussion}

The effects of 8 weeks of exposure to $\mathrm{IH}$ on the telomere lengths in the aorta and kidneys of mice is shown in Fig.1. Exposing mice to 8 weeks of IH significantly shortened telomere lengths in aortic tissues (IH: $0.85 \pm 0.02 \mathrm{~kb} /$ genome vs. IA: $0.92 \pm 0.02 \mathrm{~kb} /$ genome, $p=0.028$ ). Similarly, IH significantly shortened telomeres in renal tissues (IA: $0.77 \pm 0.03 \mathrm{~kb} /$ genome vs. $\mathrm{IH}: 0.73 \pm 0.01 \mathrm{~kb} /$ genome, $p=$ 0.031).

This study provides novel data on the effects of $\mathrm{IH}$, a hallmark of OSA, in accelerating the aging of aortic and kidney tissues as measured by telomere shortening. Our data provide a potential mechanism for the increased risk of CVD and CKD in patients with OSA. More mechanistic studies are needed to better evaluate the role of telomere shortening on other vascular tissues and to determine the potential benefits of treatments strategies such as continuous positive airway pressure (CPAP) in humans. It will also be important to design interventional studies to assess whether preserving telomere lengths can reduce the risk of CVD and CKD in patients with OSA by attenuating cellular replicative senescence in these key organs.

This study was funded by CIHR (Sleep Team Grant) and BC Lung Association

No financial disclosures were reported by the authors of this letter

\section{References}

1. Badran M, Yassin BA, Fox N, Laher I, Ayas N. Epidemiology of Sleep Disturbances and Cardiovascular Consequences. Vol. 31, Canadian Journal of Cardiology. Pulsus Group Inc.; 2015. p. 873-9.

2. Abuyassin B, Sharma K, Ayas NT, Laher I. Obstructive Sleep Apnea and Kidney Disease: A Potential Bidirectional Relationship? J Clin Sleep Med. 2015;11(8):915-24.

3. Badran M, Ayas N, Laher I. Insights into obstructive sleep apnea research. Vol. 15, Sleep Medicine. Elsevier; 2014. p. 485-95.

4. Von Zglinicki T. Oxidative stress shortens telomeres. Vol. 27, Trends in Biochemical Sciences. Elsevier Current Trends; 2002. p. 339-44.

5. Zhan Y, Hägg S. Telomere length and cardiovascular disease risk. Vol. 34, Current Opinion in Cardiology. Lippincott Williams and Wilkins; 2019. p. 270-4.

6. Ameh OI, Okpechi IG, Dandara C, Kengne AP. Association between Telomere Length, Chronic Kidney Disease, and Renal Traits: A Systematic Review. Vol. 21, OMICS A Journal of Integrative Biology. Mary Ann Liebert Inc.; 2017. p. 143-55.

7. Huang P, Zhou J, Chen S, Zou C, Zhao X, Li J. The association between obstructive sleep apnea and shortened telomere length: a systematic review and meta-analysis. Vol. 48, Sleep Medicine. Elsevier B.V.; 2018. p. 107-12.

8. Badran M, Golbidi S, Devlin A, Ayas N, Laher I. Chronic intermittent hypoxia causes endothelial dysfunction in a mouse model of diet-induced obesity. Sleep Med. 2014 May 1;15(5):596-602.

9. O'Callaghan NJ, Dhillon VS, Thomas P, Fenech M. A quantitative real-time PCR method for absolute telomere length. Biotechniques. 2008 May;44(6):807-9. 
bioRxiv preprint doi: https://doi.org/10.1101/2021.02.25.432912; this version posted February 25, 2021. The copyright holder for this preprint (which was not certified by peer review) is the author/funder, who has granted bioRxiv a license to display the preprint in perpetuity. It is made available under aCC-BY-ND 4.0 International license. 
A

Aorta

B

Kidney
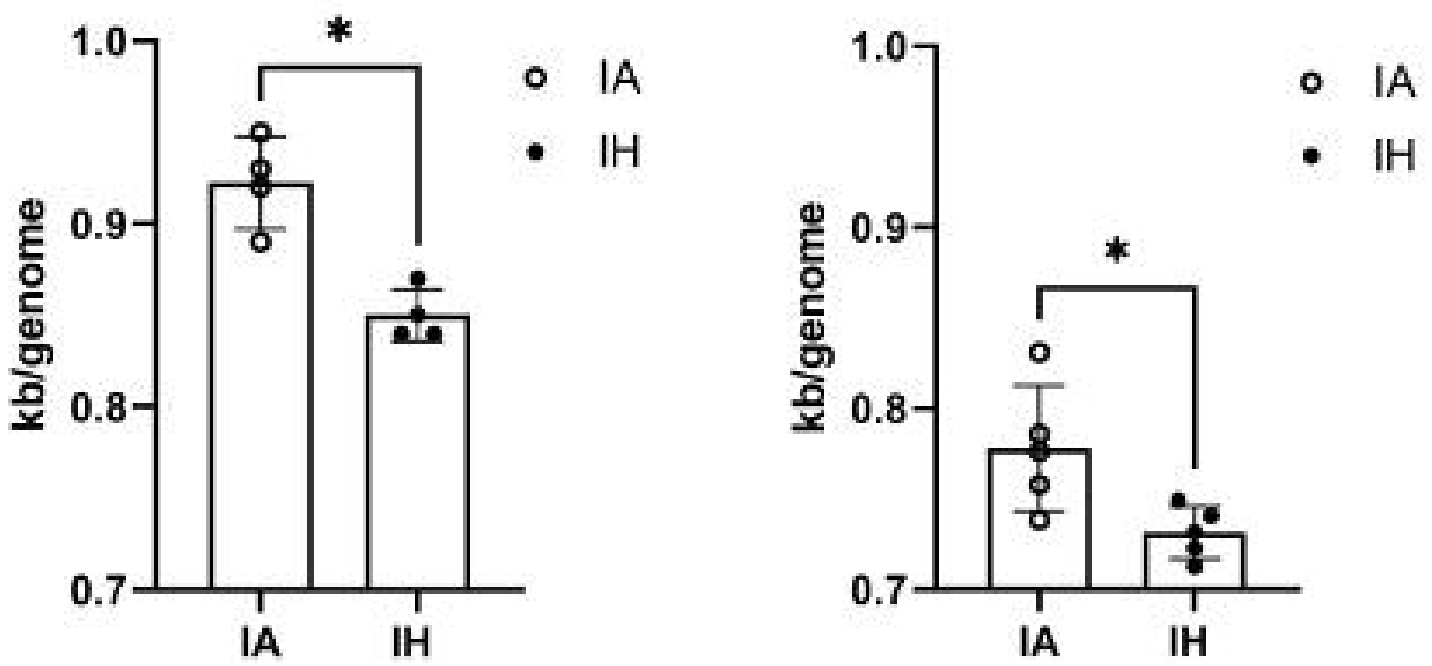